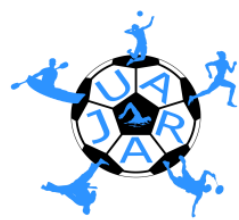

JUARA: Jurnal Olahraga

E-ISSN 2655-1896ISSN 2443-1117

https://doi.org/10.33222/juara.v5i1.704

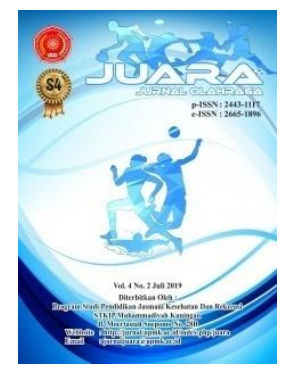

Meningkatkan Kepemimpinan dan Kerja Sama melalui Outdoor Education Camping Program

\title{
Improving Leadership and Teamwork through Outdoor Education Camping Program
}

Rafdlal Saeful Bakhri ${ }^{1}$, Arfin Deri Listiandi ${ }^{2}$, Moh. Nanang Himawan Kusuma ${ }^{3}$, Didik Rilastiyo Budi ${ }^{4}$, Topo Suhartoyo ${ }^{5}$, Rohman Hidayat ${ }^{6}$

${ }^{1}$ Department of Physical Education, Health and Recreation, STKIP Bina Mutiara Sukabumi, JI. Pembangunan, Pasirhalang, Kec. Sukaraja, Kota Sukabumi, Jawa Barat 43192, Indonesia

2,3,4,5, Department of Physical Education, Health and Recreation, Universitas Jenderal Soedirman, Jl. Profesor DR. HR Boenyamin No.708, Dukuhbandong, Grendeng, Kec. Purwokerto Utara, Kab. Banyumas, Jawa Tengah 53122, Indomesia

email: madal.rafhael@gmail.com ${ }^{1}$, arfinderilistiandi@gmail.com ${ }^{2}$, anangkusuma@ yahoo.com ${ }^{3}$, $\underline{\text { didikrilastiyobudi@yahoo.co.id }}^{4}$, topo_suhartoyo@yahoo.com ${ }^{5}$, hidayatrohman100789@gmail.com ${ }^{6}$

\section{Info Artikel}

Sejarah Artikel:

Diterima 03 September 2019

Disetujui 28 November 2019

Dipublikasikan 02 Desember 2019

Keywords:

Leadership, Teamwork, Outdoor education, and Camping program

\begin{abstract}
Abstrak
Remaja yang terlibat pada olahraga prestasi cenderung lebih fokus kepada latihan teknik dan taktik. Sedangkan keterampilan sosial merupakan aspek penting dalam perkembangan remaja sering terlupakan. Oleh karena itu diperlukan program yang dapat mengembangkan aspek keterampilan sosial, khususnya kepemimpinan dan kerja sama. Penelitian ini bertujuan untuk mengetahui pengaruh penerapan outdoor education camping program terhadap peningkatan kepemimpinan dan kerja sama pada atlet remaja klub basket dan futsal. Penelitian ini menggunakan pendekatan kuantitatif dengan metode kuasi eksperimen pretest-postest design. Jumlah subjek penelitian adalah 30 orang atlet remaja, pada klub basket dan futsal Sukabumi yang dipilih dengan menggunakan cluster random sampling. Instrumen yang digunakan berupa angket kepemimpinan dan kerja sama. Data hasil penelitian variabel keterampilan kepemimpinan diperoleh skor rata-rata pada pretest sebesar 52,2 dan posttest 56,4. Pada variabel kerja sama diperoleh skor rata-rata pretest 24,4 dan posttest 31,6. Hasil penelitian menunjukan terdapat peningkatan positif dan signifikan pada keterampilan kepemimpinan dan kerja sama.
\end{abstract}
Abstract
Teenagers who are involved in achievement oriented sports tend to focus more on technique and tactics training. Whereas social skills are important aspects in the development of teenagers is often forgotten. Therefore, a program is needed that can develop aspects of social skills, especially leadership and teamwork. This study aims to determine the effect of the application of outdoor education camping programs on improving leadership and teamwork on youth athletes in basketball and futsal clubs. This study uses a quantitative approach with a quasi- 
experimental method of pretest-posttest design. The number of research subjects were 30 teenage athletes, in Sukabumi basketball and futsal clubs who were selected using cluster random sampling. The instruments used were in the form of a leadership and teamwork questionnaire. The result of research data of the ability and leadership variable gained average score of pretest as amount 52,2 and 56,4 for its posttest. On team work variable is gained average score of pretest 24,4 and 31,16 for its posttest. The results showed that there were positive and significant improvements in leadership skills and teamwork.

(C) 2020 Rafdlal Saeful Bakhri, Arfin Deri Listiandi, Moh. Nanang Himawan Kusuma, Didik Rilastiyo Budi, Topo Suhartoyo, Rohman Hidayat Under the license CC BY-SA 4.0

\footnotetext{
${ }^{凶}$ Alamat korespondensi: J1. Pembangunan, Pasirhalang, Kec. Sukaraja, Kota Sukabumi

E-mail : madal.rafhael@gmail.com

No Handphone : 081615302003
}

\section{PENDAHULUAN}

Olahraga prestasi memiliki berbagai manfaat untuk remaja, seperti: interaksi dengan teman sebaya, pelatih dan orang dewasa dan lainnya. Berbagai hal seperti interaksi atlet remaja dengan sesame, pelatih dan orang dewasa penting dalam pengembangan karakter remaja (Gonçalves, e Silva, Cruz, Torregrosa, \& Cumming, 2010). Akan tetapi manfaat positif tersebut tidak akan muncul begitu saja, berbagai faktor lain yang dapat mempengaruhi hal tersebut diantaranya adalah lingkungan pelatihan, teman, pelatih dan orang tua (Gonçalves et al., 2010). Jelas bahwa peranan orangtua dan juga pelatih penting untuk menciptakan lingkungan yang sesuai dengan tahapan perkembang positif altet remaja. Karena selain keterampilan olahraga manfaat lain dari partisipasi remaja pada olahraga adalah keterampilan sosial (Merkel, 2013). Salah satu keterampilan sosial yang amat berkaitan dengan olahraga pada atlet remaja adalah kepemimpinan dan kerja sama.

Olahraga seperti bola basket dan futsal sangat kental dengan kepemimpinan dan kerja sama. Kepemimpinan merupakan suatu keterampilan hidup yang penting, tetapi kurang berkembang di antara atlet remaja (Gould \& Voelker, 2010). Menurut (Gaffney,
2015) kerja sama disebut-sebut sebagai pelajaran utama dalam olahraga. Kerja sama didefinisikan sebagai kemampuan yang dirasakan oleh pemuda untuk berkolaborasi dan bekerja dengan orang lain untuk mencapai tujuan bersama dalam konteks kelompok (Lower, Newman, \& AndersonButcher, 2017). Keterampilan kerja sama merupakan salah satu faktor penting dalam suatu penampilan olahraga, selain itu kerja sama juga merupakan salah satu dari perkembangan positif remaja (Harun \& Salamuddin, 2014; Lower, Newman, \& Anderson-butcher, 2015; Mcdonald \& Messinger, 2013; Norton \& Watt, 2014). Keterampilan kepemimpinan dan kerja sama pada atlet remaja jelas merupakan sesuatu yang sangat penting untuk dikembangkan, maka diperlukan sebuah program khusus untuk mengembangkan kedua aspek tersebut.

$$
\text { Pengembangan keterampilan }
$$

kepemimpinan dan kerja sama pada atlet remaja tentunya memerlukan pertimbangan yang terkait dengan masa perkembangan positif remaja. Salah satu program kegiatan yang banyak digunakan untuk mendukung perkembangan positif pada remaja adalah program outdoor education (Enoksen \& Lynch, 2018; Gartner-Manzon \& Giles, 2018). Outdoor education mampu meningkatkan berbagai aspek perkembangan 
remaja seperti kerja sama, kepemimpinan, keterampilan sosial dan tanggung jawab (Bruner, Eys, \& Carreau, 2016; GartnerManzon \& Giles, 2018; Gau, Chang, \& Kuo, 2016; Harun \& Salamuddin, 2014; Johnson \& Chin, 2016). Terdapat beberapa jenis kegiatan outdoor education, salah satunya adalah camping. Outdoor education melalui program camping berpotensi untuk meningkatkan keterampilan kerja sama (Gartner-Manzon \& Giles, 2018; Gau et al., 2016).

Camping memberikan peluang remaja untuk hidup dan berinteraksi langsung dengan alam bebas (Andersson \& Öhman, 2015). Dalam kegiatannya mereka dapat mengembangkan berbagai hal melalui kegiatan yang memberikan pengalaman menyenangkan. Beberapa kegiatan utama dalam camping adalah:

1. Mendirikan dan Membongkar Tenda: Peserta dituntut untuk dapat mendirikan serta membongkar tenda, menjaga lingkungan dan memastikan area tenda aman dari berbagai ancaman.

2. Masak Rimba: Peserta dituntut untuk dapat memanfaatkan perlengkapan yang terbatas, dan bahan makanan sederhana.

3. Fire Camp: Kegiatan ini diantaranya adalah a). menyusun dan menyalakan api unggun, b). Night Games, c). performance, d). Story Telling, e). memadamkan api unggun.

4. Hiking: Kegiatan ini dilakukan agar peserta dapat melakukan penjelajahan dan mendapatkan pengalaman bermakna. Kegiatan ini cukup kental dengan aktivitas fisik, karena menuntut para peserta untuk berjalan menempuh jarak yang relatif jauh.

5. Games: Berbagai permainan sering kali diterapkan dalam kegiatan outdoor. Jenis permainan yang digunakan dalam kegiatan ini adalah a). Ice Breaking, b). Leadership Games, dan c). Team Building Games.

Rangkaian kegiatan camping tersebut sesuai untuk atlet remaja, karena mengandung unsur aktivitas fisik di dalamnya. Outdoor education memberikan peluang remaja untuk berpartisipasi dalam aktivitas fisik (Finn, Yan, \&McInnis, 2018). Salah satu kegiatan dalam program camping ini yang sangat menuntut aktivitas fisik adalah hiking. Selain itu, kegiatan games juga berkaitan dengan aktivitas fisik. Outdoor education melibatkan remaja dengan berbagai tingkat kebugaran dan keterampilan untuk dapat berpartisipasi dalam aktivitas fisik yang intens dan menyenangkan (Finn et al., 2018). Keterkaitan antara outdoor education dengan aktivitas fisik terbukti dengan hasil penelitian (Finn et al., 2018) yang menunjukan outdoor education dapat meningkatkan partisipasi aktivitas fisik siswa. Rangkaian program camping yang juga berkaitan dengan aktivitas fisik ini disinyalir dapat memberikan perubahan positif pada aspek keterampilan kepemimpinan dan kerja sama.

Berkaitan dengan penelitian ini, terdapat beberapa penelitian terdahulu. Penelitian (Harun \& Salamuddin, 2014) yang berjudul "Promoting Social Skills through Outdoor Education and Assessing Its' Effects". Hasil penelitian tersebut menyimpulkan bahwa terdapat pengaruh program outdoor education terhadap keterampilan sosial: kepemimpinan dan kerja sama pada remaja. Selanjutnya penelitian (Gau et al., 2016) "Examining the correlates of exploration activities for senior high school students in Taiwan." Hasil penelitian menunjukan bahwa terdapat pengaruh yang signifikan program camping terhadap keterampilan kerja sama remaja. Selain itu penelitian (Yeap, Mokhtar, Muslimen, Ghazali, \& Tarmizi, 2016) "Outdoor-Based Education Camp: An Essential Tool to Promote Leadership Skills." Hasil penelitian menunjukan bahwa siswa menjadi lebih menyadari pentingnya keterampilan kepemimpinan setelah mengikuti kegiatan camping.

Berdasarkan beberapa penelitian terdahulu dapat disimpulkan bahwa penerapan 
outdoor education cenderung diterapkan pada siswa maupun mahasiswa. Peneliti ingin menerapkan pada konteks yang berbeda, yaitu pada atlet remaja. Penelitian yang mengintegrasikan program outdoor education dengan perkembangan keterampilan sosial pada atlet sangat jarang, terutama di Indonesia khususnya di Sukabumi. Selanjutnya berdasarkan pengamatan peneliti, aspek keterampilan sosial, terutama dalam kepemimpinan dan kerja sama kurang diperhatikan karena para pelatih lebih terfokus kepada aspek teknik dan taktik. Sedangkan aspek keterampilan sosial sering terlupakan. Dari peninjauan tersebut peneliti ingin menerapkan outdoor education melalui program camping terhadap kepemimpinan dan kerja sama pada atlet remaja cabang olahraga bola basket dan futsal.

Kepemimpinan dan kerja sama merupakan salah satu aspek penting yang harus dimiliki oleh setiap atlet remaja, khususnya dalam cabang olahraga bola basket dan futsal. Meskipun terlibat dalam olahraga prestasi, atlet remaja memerlukan suatu kegiatan yang sesuai dengan tahapan perkembangan usianya. Outdoor education melalui program camping memiliki potensi besar untuk mengembangkan keterampilan kepemimpinan dan kerja sama pada atlet remaja bola basket dan futsal. Akan tetapi, penelitian yang mengintegrasikan antara outdoor education pada atlet remaja masih terbatas. Keberadaan penelitian ini dapat menjadi salah satu dukungan terhadap teori dan atau hasil penelitian sebelumnya. Penelitian ini dapat menjadi salah satu inovasi perpaduan suatu program outdoor education dengan olahraga prestasi, khususnya pada tingkat regional.

\section{METODE}

Pendekatan penelitian yang digunakan adalah pendekatan kuasi eksperimen dengan menggunakan one group pretest-posttest design (Maksum, 2012). Populasi dalam penelitian ini adalah Klub Basket dan Futsal Kecamatan Cicurug Kabupaten Sukabumi. Sampel dipilih dengan menggunakan teknik cluster random sampling. Hasil sampling diperoleh masing-masing satu klub bola basket dan satu klub futsal dengan jumlah keseluruhan 30 orang sampel dengan usia antara $13-15$ tahun.

Pengumpulan data dilakukan dengan memberikan lembar angket kepemimpinan dan kerja sama kepada sampel penelitian. Jenis angket yang digunakan berupa angket tertutup yang menyediakan beberapa pilihan atau alternatif jawaban kepada sampel penelitian. Pengumpulan data dilakukan pada saat pretest dan posttest.

Angket kepemimpinan dalam penelitian ini merupakan hasil adaptasi dari angket Peer Sport Leadership Behavior Inventory (PSLBI) dengan nilai validitas 0,84 dan reliabilitas 0,92. "Athletes rate their own leadership ability on a 7-point Likert scale that ranges from 1 (never like me) to 7 (always like me)." (Price \& Weiss, 2011). Angket menggunakan skala Likert 7 alternatif jawaban, yaitu "1) Tidak sama sekali, 2) Pernah, 3) Terkadang, 4) Cukup sering, 5) Sering, 6) Sering sekali, dan 7) Selalu". Angket tersebut telah disesuaikan dengan kebutuhan penelitian dengan jumlah 14 pernyataan. Hasil uji coba ulang angket menunjukan validitas $0,580-0,897$ dan reliabilitas 0,930 . Seluruh butir pernyataan memenuhi standar.

Angket kerja sama yang digunakan dalam penelitian ini merupakan angket yang diadaptasi dari The Teamwork Scale for Youth, dengan validitas 0,646 dan reliabilitas 0,856 (Lower et al., 2015, p. 6). "Items are assessed on a 5-point Likert-type scale ranging from 1 (not at all true) to 5 (really true)" (Lower et al., 2015, p. 3). Angket tersebut memiliki 8 butir pernyataan dengan menggunakan skala Likert 5 alternatif jawaban, yaitu "1) Sangat Tidak Setuju, 2) Tidak Setuju, 3) Sedikit Setuju, 4) Setuju, dan 5) Sangat Setuju". 
Angket tersebut telah disesuaikan dengan kebutuhan penelitian dan dilakukan uji coba ulang. Hasil uji coba instrument menunjukan nilai validitas $0,582-0,898$ dan reliabilitas 0,876 . Seluruh butir pernyataan memenuhi standar validitas dan reliabitias.

Analisis data yang dilakukan dalam penelitian ini adalah: 1). Uji Normalitas data dilakuan melalui uji Kolmogorov smirnov z; 2). Uji Homogenitas data menggunakan uji varians; dan 3). Uji Hipotesis menggunakan uji Paired Sample $t$ test. Analisis data yang dibantu dengan software SPSS versi 22.

\section{HASIL DAN PEMBAHASAN \\ Hasil}

Berikut merupakan data keterampilan kepemimpinan yang ditampilkan pada Tabel 1. Pada Tabel 1. menunjukan deskripsi data hasil penelitian pada variabel keterampilan kepemimpinan atlet remaja. Data menunjukan jumlah skor pada pretest 1567, dan posttest 1691, skor gain (selisih) 124. Rata-rata pada pretest 52,2 dan posttest 56,4 dengan skor gain 4,1 . Skor minimal pada pretest 45 , dan posttest 50 , skor gain 0. Skor maksimal pada pretest 63, danposttest 65, skor gain 9.

Tabel dan grafik 1 Deskripsi Data Kepemimpinan

\begin{tabular}{lccc} 
& Pretest & Posttest & Gain \\
\hline Jumlah & 1567 & 1691 & 124 \\
Rata-rata & 52,2 & 56,4 & 4,1 \\
SD & 4,3 & 3,7 & 2,5 \\
Minimal & 45 & 50 & 0 \\
Maksimal & 63 & 65 & 9 \\
\hline
\end{tabular}

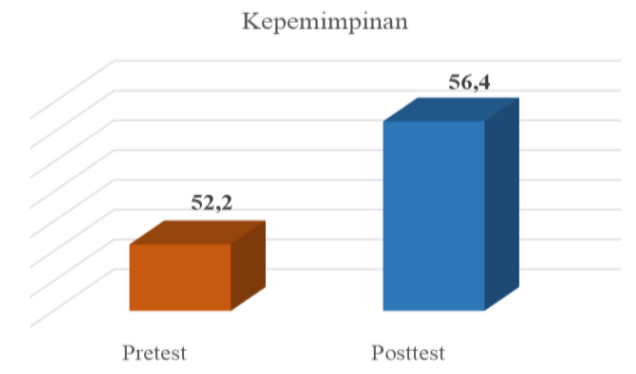

Tabel 2. menunjukan deskripsi data hasil penelitian pada variable kerja sama atlet remaja. Data menunjukan jumlah skor pada pretest 733 dan posttest 947 skor gain 214. Rata-rata pada pretest 24,4 dan posttest 31,6

dengan skor gain 7,1. Skor minimal pada pretest 20 , dan posttest 27 , skor gain 0 . Skor maksimal pada pretest 30, dan posttest 39, skor gain 13 .

Tabel dan grafik 2 Data Kerja Sama

\begin{tabular}{lccc} 
& Pretest & Posttest & Gain \\
\cline { 2 - 4 } Jumlah & 733 & 947 & 214 \\
Rata-rata & 24,4 & 31,6 & 7,1 \\
SD & 2,6 & 2,8 & 3,3 \\
Minimal & 20 & 27 & 0 \\
Maksimal & 30 & 39 & 13 \\
\hline
\end{tabular}

Uji hipotesis penelitian menggunakan uji t berpasangan atau Paired Sampel t test. Uji ini dilakukan untuk mengetahui pengaruh dari perlakuan yang telah diberikan dengan cara

Tabel 3. Hasil Uji Hipotesis

membandingkan data pretest dengan postest. Adapun hasil dari pengujiannya dapat dilihat pada Tabel 3.

\begin{tabular}{lcc}
\hline Variabel & $\mathrm{t}$ & Sig. \\
\hline Kepemimpinan & 9,204 & 0,000
\end{tabular}




Kerja sama $\quad 11,772 \quad 0,000$

Pada Tabel 3. Untuk keterampilan kepemimpinan menunjukan nilai $\mathrm{t}=9,204$ dan sig $=0,000<0,05$ maka Ho ditolak, atau terdapat pengaruh outdoor education melalui program camping terhadap keterampilan kepemimpinan pada atlet remaja bola basket dan futsal. Pada keterampilan kerja sama menunjukan nilai $\mathrm{t}=11,772$ dan $\mathrm{sig}=0,000<$ 0,05 maka Ho ditolak, atau terdapat pengaruh outdoor education melalui program camping terhadap kerja sama pada atlet remaja bola basket dan futsal.

\section{Pembahasan}

Penelitian ini menggunakan pendekatan kuantitatif dengan metode kuasi eksperimen dengan menerapkan outdoor education camping program sebagai perlakukan. Program camping dilaksanakan selama tiga kali pertemuan, masingmasing pertemuan dilakukan selama tiga hari dua malam. Perlakuan yang diberikan dirancang khusus untuk tingkatan usia atlet remaja dengan sasaran pengembangan keterampilan kepemimpinan dan kerja sama.

Hasil penelitian ini mendukung hasil penelitian sebelumnya. Penelitian yang dilakukan oleh (Harun \& Salamuddin, 2014) juga menunjukan bahwa program outdoor education memberikan pengaruh positif yang signifikan terhadap kepemimpinan pada remaja. Penelitian tersebut menggunakan siswa remaja sebagai sampel penelitian. Berbeda dengan penelitian ini yang mengintegrasikan olahraga prestasi, dalam hal ini atlet remaja yang diberikan perlakuan outdoor education camping program untuk meningkatkan kepemimpinan.

Pada saat penelitian berlangsung terdapat hal menarik yang terjadi terkait aspek keterampilan kepemimpinan atlet remaja. Beberapa siswa yang pada awalnya nampak kurang dominan dalam kelompoknya mampu menunjukan perubahan yang cukup mencolok. Beberapa hal tersebut diantaranya mampu menyampaikan pendapat mengenai pemecahan suatu masalah, dapat membantu dan mengarahkan rekan satu kelompoknya, serta menunjukan kreativitas dalam menghadapi berbagai situasi yang ada. Selain dari pada itu beberapa atlet remaja juga menunjukan keberanian untuk dapat memimpin kelompoknya pada saat hiking. Dalam outdoor education mengembangkan keterampilan kepemimpinan peserta melalui berbagai kegiatan menantang yang terfokus pada kerja sama (mengajak dan mengarahkan rekan kelompoknya), menciptakan lingkungan positif, komunikasi dan berbagai keterampilan kepemimpinan lainnya (GartnerManzon \& Giles, 2018).

Kepemimpinan merupakan salah satu keterampilan yang sangat penting dimiliki oleh remaja, karena keterampilan ini dapat menuntun remaja untuk menjadi pribadi yang lebih baik di masa depan (Gould \& Voelker, 2010; Seemiller, 2018). Keterampilan kepemimpinan juga terkait dengan beberapa aspek keterampilan lainnya, seperti keterampilan komunikasi yang efektif, kerja sama, pemecahan masalah, pengambilan keputusan, dan penetapan tujuan (Armour \& Sandford, 2013; Seemiller, 2018).

Kepemimpinan merupakan aspek mendasar yang bisa mendukung kinerja dalam olahraga, khususnya dalam olahraga tim atau beregu (Cotterill \& Fransen, 2016), karena dalam olahraga beregu harus ada sosok pemimpin yang bisa memberikan motivasi serta mewakili pelatih saat dilapangan oleh karena itu dalam olahraga beregu terdapat kapten tim. Ketika seorang pemimpin bisa bertanggung jawab, kompeten hingga percaya diri maka akan terjadi tingkat kepercayaan yang tinggi dari rekan-rekan satu timnya yang akan berdampak baik bagi kerja sama tim dalam suatu pertandingan (GulakLipka, 2017). Berkaitan dengan kecabangan olahraga bola basket dan futsal keterampilan kepemimpinan bagi atlet remaja ini tentunya akan sangat berharga guna menunjang prestasi di masa mendatang. 
Hasil penelitian ini juga menunjukan bahwa outdoor education melalui program camping mampu meningkatkan keterampilan kerja sama pada atlet remaja bola basket dan futsal Kecamatan Cicurug Kabupaten Sukabumi. Hasil penelitian ini mendukung penelitian sebelumnya, yaitu penelitian (Gau et al., 2016) "Examining the correlates of exploration activities for senior high school students in Taiwan." Hasil penelitian tersebut menunjukan bahwa terdapat pengaruh yang signifikan program camping terhadap keterampilan kerja sama remaja.

Berbagai kegiatan yang terdapat dalam outdoor education program camping terbukti menunjang para atlet remaja untuk dapat meningkatkan kerja sama. Utamanya kegiatan tersebut merupakan berbagai aktivitas dan tugas kelompok. Pada umumnya sebagian besar kegiatan dirancang menggunakan sistem kelompok. Setiap kelompok memiliki tugas yang harus diselesaikan bersama-sama. Pada saat masing-masing kelompok mendapatkan tugas untuk mendirikan tenda dalam waktu yang ditentukan. Untuk dapat menyelesaikan tugas tersebut diperlukan kerja sama yang baik dalam setiap kelompok, baik itu dalam pembagian tugas atau pelaksanaan serta penyelesaian peranan atau tugas yang telah disepakati.

Terdapat berbagai hal menarik yang nampak terjadi pada saat penelitian berlangsung. Pertama, terdapat beberapa orang sampel yang menunjukan peningkatan keterlibatan dalam kelompok. Pada pertemuan awal beberapa orang tersebut terlihat kurang aktif dalam hal komunikasi dan membantu untuk menyelesaikan tugas kelompok. Seperti halnya pada saat kegiatan permainan yang menuntut sampel untuk bekerja sama dengan rekan kelompoknya. Situasi tersebut memicu sampel untuk berusaha lebih baik agar dapat menyelesaikan tugas, yang pada akhirnya tanpa disadari membuat mereka saling bekerja sama.

Kerja sama merupakan keterampilan positif yang harus dimiliki oleh remaja sebagai bekal menjadi pribadi dewasa. Dalam bidang olahraga, keterampilan kerja sama merupakan salah satu faktor penting dalam suatu penampilan (Harun \& Salamuddin, 2014; Lower et al., 2015; Mcdonald \& Messinger, 2013; Norton \& Watt, 2014). Menurut (Gaffney, 2015) kerja sama disebut-sebut sebagai pelajaran utama dalam olahraga.

Dalam kecabangan olahraga basket dan futsal kerja sama juga merupakan aspek penting yang tentunya harus dimiliki oleh para atlet. Berkaitan dengan hal tersebut terdapat suatu istilah bahwa: lebih baik menjadi tim yang baik daripada menonjolnya salah satu individu saja, kerja sama merupakan kultur atau kebiasaan yang harus selalu ditekankan terhadap atlet khususnya dalam cabang olahraga beregu (Halldorsson, Thorlindsson, \& Katovich, 2017; McEwan \& Beauchamp, 2014).

Pentingya keterampilan kepemimpinan dan kerja sama bagi atlet remaja merupakan suatu hal yang harus disadari oleh berbagai pihak terkait (pelatih, official, orang tua, dan juga guru pendidikan jasmani). Berdasarkan hal tersebut penelitian yang telah dilakukan ini diharapkan dapat menjadi salah satu rujukan agar dapat melakukan kegiatan guna menunjang berbagai aspek perkembangan positif remaja, khususnya pada keterampilan kepemimpinan dan kerja sama.

\section{SIMPULAN}

Kesimpulan dalam penelitian ini adalah terdapatnya pengaruh yang positif dan signifikan outdoor education melalui program camping terhadap peningkatan keterampilan kepemimpinan dan kerja sama pada atlet remaja bola basket dan futsal Kecamatan Cicurug Kabupaten Sukabumi. Hasil penelitian ini memberikan beberapa saran sebagai berikut:1) Penelitian ini menggunakan sampel atlet remaja tingkat regional, pengembangan selanjutnya dapat menggunakan sampel atlet elit; 2) Instrumen penelitian yang digunakan dapat dikembangkan dengan menambahkan format observasi; 3) Pendekatan penelitian pada 
kajian dalam penelitian ini juga dapat berupa pendekatan kualitatif.

\section{UCAPAN TERIMAKASIH}

Dalam Penelitian ini kami mengucapkan terima kasih kepada ketua STKIP Bina Mutiara Sukabumi yang selalu memberikan dukungan pada penulis dan kami mengucapkan terima kasih yang sebesar-besarnya kepada Kementerian Riset, Teknologi dan Pendidikan Tinggi yang telah memberikan dana hibah penelitian sehingga penelitian ini dapat terselenggara dengan baik.

\section{DAFTAR PUSTAKA}

Andersson, K., \& Öhman, J. (2015). Moral relations in encounters with nature. Journal of Adventure Education and Outdoor Learning, 15(4), 310-329. https://doi.org/10.1080/14729679.2015.10 35292

Armour, K., \& Sandford, R. (2013). Positive youth development through an outdoor physical activity programme evidence from a four year evaluation. Educational Review, 65(1), 85-108. https://doi.org/10.1080/00131911.2011.64 8169

Bruner, M., Eys, M., \& Carreau, J. (2016). Utilizing the Team Environment AssessMent (TEAM) to enhance team building in sport. Journal of Sport \& Exercise Psychology, 38(1993), 164.

Cotterill, S. T., \& Fransen, K. (2016). Athlete leadership in sport teams: Current understanding and future directions. International Review of Sport and Exercise Psychology, 9(1), 116-133. https://doi.org/10.1080/1750984X.2015.1 124443

Enoksen, E., \& Lynch, P. (2018). Learning leadership: becoming an outdoor leader. Journal of Adventure Education and Outdoor Learning, 18(2), 176-188. https://doi.org/10.1080/14729679.2017.13 91105
Finn, K. E., Yan, Z., \& McInnis, K. J. (2018). Promoting Physical Activity and Science Learning in an Outdoor Education Program. Journal of Physical Education, Recreation and Dance, 89(1), 35-39. https://doi.org/10.1080/07303084.2017.13 90506

Gaffney, P. (2015). The nature and meaning of teamwork. Journal of the Philosophy of Sport, 42(1), 1-22. https://doi.org/10.1080/00948705.2014.94 1849

Gartner-Manzon, S., \& Giles, A. R. (2018). Lasting impacts of an Aboriginal youth leadership retreat: a case study of Alberta's Future Leaders Program. Journal of Adventure Education and Outdoor Learning, OO(00), 1-15. https://doi.org/10.1080/14729679.2018.14 70937

Gau, L.-S., Chang, I.-H., \& Kuo, C.-H. (2016). Examining the correlates of exploration activities for senior high school students in Taiwan. Journal of Sport \& Exercise Psychology, 38, 191.

Gonçalves, C. E., e Silva, M. J. C., Cruz, J., Torregrosa, M., \& Cumming, S. P. (2010). The effect of achievement goals on moral attitudes in young athletes. Journal of Sports Science and Medicine, 9(4), 605-611.

Gould, D., \& Voelker, D. K. (2010). Youth sport leadership development: Leveraging the sports captaincy experience. Journal of Sport Psychology in Action, 1(1), 1-14. https://doi.org/10.1080/21520704.2010.49 7695

Gulak-Lipka, P. (2017). The Role of Trust for Leadership in Team Sports. Journal of Corporate Responsibility and Leadership, 3(3), 39. https://doi.org/10.12775/jcrl.2016.015

Halldorsson, V., Thorlindsson, T., \& Katovich, M. A. (2017). Teamwork in sport: a sociological analysis. Sport in Society, 20(9), 1281-1296. 
https://doi.org/10.1080/17430437.2017.12 84798

Harun, M. T., \& Salamuddin, N. (2014). Promoting social skills through outdoor education and assessing its' effects. Asian Social Science, 10(5), 71-78. https://doi.org/10.5539/ass.v10n5p71

Johnson, J., \& Chin, J. W. (2016). Hazing rites/rights: using outdoor- and adventure education-based orientation to effect positive change for first-year athletes. Journal of Adventure Education and Outdoor Learning, 16(1), 16-30. https://doi.org/10.1080/14729679.2015.10 50681

Lower, L. M., Newman, T. J., \& Andersonbutcher, D. (2015). Validity and Reliability of the Teamwork Scale for Youth. Research on Social Work Practice, (May 2016), 1-10. https://doi.org/10.1177/104973151558961 4

Lower, L. M., Newman, T. J., \& AndersonButcher, D. (2017). Validity and Reliability of the Teamwork Scale for Youth. Research on Social Work Practice, 27(6), 716-725. https://doi.org/10.1177/104973151558961 4

Maksum, A. (2012). Metodologi Penelitian dalam Olahraga. Surabaya: Universitas Negeri Surabaya.

Mcdonald, N. M., \& Messinger, D. S. (2013). The Development of Empathy: How, When and Why. Free Will, Emotions, and Moral Actions: Philosophy and Neuroscience in Dialogue, 1-36.

McEwan, D., \& Beauchamp, M. R. (2014). Teamwork in sport: a theoretical and integrative review. International Review of Sport and Exercise Psychology, 7(1), 229-250.

https://doi.org/10.1080/1750984X.2014.9 32423

Merkel, D. L. (2013). Youth sport: positive and negative impact on young athletes. Open Access Journal of Sports Medicine, 4, 151-160. https://doi.org/10.2147/OAJSM.S33556

Norton, C. L., \& Watt, T. T. (2014). Exploring the Impact of a Wilderness-Based Positive Youth Development Program for Urban Youth. Journal of Experiential Education, 37(4), 335-350. https://doi.org/10.1177/105382591350311 3

Price, M. S., \& Weiss, M. R. (2011). Journal of Applied Sport Psychology Peer Leadership in Sport: Relationships among Personal Characteristics, Leader Behaviors, and Team Outcomes. Journal of Applied Sport Psychology, 21(November 2014), 49-64. https://doi.org/10.1080/10413200.2010.52 0300

Seemiller, C. (2018). A Competency-Based Model for Youth Leadership Development. Journal of Leadership Education, 17(1), 56-72. https://doi.org/10.12806/V17/I1/R1

Yeap, E. E. L., Mokhtar, R., Muslimen, M. A., Ghazali, F., \& Tarmizi, M. A. A. (2016). Outdoor-Based Education Camp: An Essential Tool to Promote Leadership Skills. International Journal of Information and Education Technology, 6(5), 352-356. https://doi.org/10.7763/IJIET.2016.V6.71 3 